\title{
Editorial Challenge: From a Quarterly to a Bimonthly Journal
}

\author{
F.G. Filip, I. Dzitac
}

\author{
Florin Gheorghe Filip \\ Editor in Chief of IJCCC, \\ Romanian Academy, Bucharest, Romania \\ ffilip@acad.ro
}

\section{Ioan Dzitac}

Associate Editor in Chief of IJCCC,

Aurel Vlaicu University of Arad, Romania \&

Agora University, Oradea, Romania

rector@univagora.ro

\begin{abstract}
:
Starting with issue 4 of volume 7(2012) International Journal of Computers Communications \& Control (INT J COMPUT COMMUN, IJCCC) [4] is a member of, and subscribes to the principles of, the Committee on Publication Ethics (COPE) [2]. Beginning with issue 1 of volume 8(2013) IJCCC will be published as a bimonthly journal (6 issues/year) [5].
\end{abstract}

Keywords: ethics, bimonthly journal, impact factor.

\section{Why a bimonthly journal?}

In the period 2006-2012 the International Journal of Computers, Communications \& Control, ISSN 1841-9836, has been published as a quarterly journal (4issues/year), with a supplementary issue every even year (5 issues/year) and has been covered in SCI Expanded [3] starting with the supplementary issue S of volume 1(2006) and has been indexed in Journal Citation Reports/Science Edition (JCR), with 3-years Journal Impact Factor 0.373 (in JCR2009), 0.650 (in JCR2010) and 0.438 (in JCR2011). This decreasing of the last impact factor can be explained by increasing of the number of published papers in issue 5 (December, 2010). Consequently many papers can be cited only in 2012, but no more in 2011, the year considered for Journal Impact Factor calculation in JCR2011. The correction of this anomalous fluctuation of the impact factor might be solved by a change of publishing policy of IJCCC, from a irregular frequency of publication (4-5 issues/year) to a bimonthly publication (6 issues/year) with a regular frequency. This new policy is sustainable because in the last two years we have received over 1,200 manuscripts.

Publication frequency starting with issue 1 of volume 8(2013): IJCCC will be published as a bimonthly journal (6 issues/ year), with a regular schedule such as: Issue 1 (February); Issue 2 (April); Issue 3 (June); Issue 4 (August); Issue 5 (October); Issue 6 (December).

\section{Focus and Scope. Topics}

IJCCC is directed to the international communities of scientific researchers in computer and control from the universities, research units and industry. To differentiate from other similar journals, the editorial policy of IJCCC encourages the submission of scientific papers that focus on the integration of the 3 " $\mathrm{C}$ " (Computing, Communication, Control). In particular the following topics are expected to be addressed by authors:

1. Integrated solutions in computer-based control and communications;

2. Computational intelligence methods (with particular emphasis on fuzzy logic-based methods, ANN, evolutionary computing, collective/swarm intelligence); 
3. Advanced decision support systems (with particular emphasis on the usage of combined solvers and/or web technologies).

\section{Author Guidelines}

\section{Length of a manuscript}

The maximum number of pages of one article is 16 . The publishing of a 6 page article is free of charge. For each supplementary page there is a fee of $50 \mathrm{EUR} /$ page that must be paid after receiving the acceptance for publication.

\section{Technical Instructions for Authors}

The papers must be written in English. The first page of the paper must contain title of the paper, name of author(s), an abstract of about 300 words and 3-5 keywords. The name, affiliation (institution and department), regular mailing address and email of the author(s) should be filled as in [1].

Manuscripts must be accompanied by a signed copyright transfer form. The copyright transfer form is available at website.

Initial submission (manuscript for review: The manuscript can be write in LaTex by the IJCCC template or in MS Word format with the following specifications: paper A4, font TNR $12 \mathrm{p}$, single column. The manuscript must be uploaded online in journal management and publishing system of IJCCC (open source software: Open Journal Systems developed by the Public Knowledge Project) [5].

Final submission (accepted paper for publication: Checklist of documents which must be send by e-mail: Completed copyright transfer form; Source files (One LaTeX file for the text, EPS files for figures - they must reside in a separate folder); Final PDF file (for reference).

\section{Peer Review Process}

The submissions will be revised independently by minimum two reviewers and will be accepted for publication only after end of the editorial workflow.

Evaluation period and rejection rate information:

- Evaluation period after paper submission: up to 6 months;

- Publication time is pending on the number of papers received. We aim at a time not longer than one year;

- Mean acceptance rate: of approximately $20 \%$.

\section{Bibliography}

[1] Andonie R., Dzitac I., How to Write a Good Paper in Computer Science and How Will It Be Measured by ISI Web of Knowledge, INT J COMPUT COMMUN, ISSN 1841-9836, $5(4): 432-446$.

[2] Committee on Publication Ethics (COPE) (http://publicationethics.org).

[3] http://ip-science.thomsonreuters.com/cgi-bin/jrnlst/jlresults.cgi?PC=D\&ISSN=1841-9836.

[4] http://www.journal.univagora.ro (IJCCC archive for 2006-2012).

[5] http://univagora.ro/jour/index.php/ijccc/ (New IJCCC website). 